\title{
Boldine, an Alkaloid from Peumus boldus Molina, Induces Endothelium-Dependent Vasodilation in the Perfused Rat Kidney: Involvement of Nitric Oxide and Small-Conductance $\mathrm{Ca}^{2+}$ - Activated $\mathrm{K}^{+}$Channel
}

\author{
Priscila de Souza $\mathbb{D}^{1},{ }^{1}$ Rita de Cássia Vilhena da Silva, ${ }^{1}$ Luisa Mota da Silva, ${ }^{1}$ \\ Viviane Miranda Bispo Steimbach, ${ }^{1}$ Karyne Garcia Tafarelo Moreno, ${ }^{2}$ \\ and Arquimedes Gasparotto Junior $\mathbb{D i D}^{2}$ \\ ${ }^{1}$ Graduate Program in Pharmaceutical Sciences, Nucleus of Chemical-Pharmaceutical Investigations (NIQFAR), \\ University of Vale do Itajaí, Itajaí, SC, Brazil \\ ${ }^{2}$ Laboratory of Electrophysiology and Cardiovascular Pharmacology, Faculty of Health Sciences, \\ Universidade Federal da Grande Dourados, Dourados, Mato Grosso do Sul, Brazil
}

Correspondence should be addressed to Priscila de Souza; priscilasouza_rc@yahoo.com.br

Received 11 September 2021; Revised 11 January 2022; Accepted 17 January 2022; Published 16 February 2022

Academic Editor: Adolfo Andrade-Cetto

Copyright (C) 2022 Priscila de Souza et al. This is an open access article distributed under the Creative Commons Attribution License, which permits unrestricted use, distribution, and reproduction in any medium, provided the original work is properly cited.

\begin{abstract}
Boldine, 2,9-dihydroxy-1,10-dimethoxyaporphine, is the main alkaloid found in the leaves and bark of Peumus boldus Molina. In recent years, boldine has demonstrated several pharmacological properties that benefit endothelial function, blood pressure control, and reduce damage in kidney diseases. However, the renal vasodilator effects and mechanisms remain unknown. Herein, perfused rat kidneys were used to study the ability of boldine to induce vasodilation of renal arteries. For that, left kidney preparations with and without functional endothelium were contracted with phenylephrine and received 10-300 nmol boldine injections. The preparations were then perfused for $15 \mathrm{~min}$ with phenylephrine plus L-NAME, indomethacin, $\mathrm{KCl}$, tetraethylammonium, glibenclamide, apamin, charybdotoxin, or iberiotoxin. In 30, 100, and $300 \mathrm{nmol}$ doses, boldine induced a dose-and endothelium-dependent relaxing effect on the renal vascular bed. No vasodilator effects were observed in preparations lacking functional endothelium. While the inhibition of the cyclooxygenase enzyme through the addition of indomethacin did not cause any change in the vasodilating action of boldine, the nonselective nitric oxide synthase inhibitor L-NAME fully precluded the vasodilatory action of boldine at all doses tested. The perfusion with $\mathrm{KCl}$ or tetraethylammonium (nonselective $\mathrm{K}^{+}$channels blocker) also abolished the vasodilatory effect of boldine, indicating the participation of $\mathrm{K}^{+}$channels in the renal action of boldine. The perfusion with glibenclamide (selective ATP-sensitive $\mathrm{K}^{+}$channels blocker), iberiotoxin (selective high-conductance $\mathrm{Ca}^{2+}$-activated $\mathrm{K}^{+}$channel blocker), and charybdotoxin (selective high- and intermediate-conductance $\mathrm{Ca}^{2+}$-activated $\mathrm{K}^{+}$channel blocker) did not modify the vasodilatory action of boldine. On the other hand, the perfusion with apamin (selective small-conductance $\mathrm{Ca}^{2+}$-activated $\mathrm{K}^{+}$channel blocker) completely prevented the vasodilatory action of boldine at all doses tested. Together, the present study showed the renal vasodilatory properties of boldine, an effect dependent on the generation of nitric oxide and the opening of a small-conductance $\mathrm{Ca}^{2+}$-activated $\mathrm{K}^{+}$channel.
\end{abstract}

\section{Introduction}

Peumus boldus Molina, popularly known as "boldo" or "boldu", is a tree species belonging to the Monimiaceae family and native to central and southern Chile, where it occurs abundantly. In addition to popular use for the treatment of several ailments, widely known for gastric and liver disorders, boldo-based preparations are described in several official pharmacognostic texts, such as official pharmacopeias in Brazil, Chile, Germany, Portugal, Romania, Spain, and Switzerland $[1,2]$. 
Boldo's active principles have been described in essential oils (ascaridol, cineol, esters, aldehydes, ketones, and hydrocarbons), alkaloids (boldine, isoboldine, and others), glycosides, and others (flavonoids, citric acid, gum, sugars, tannins, minerals, lipids, etc.). The barks are richer in alkaloids [3]. Most of the pharmacological studies of boldo describe the activities observed for the alkaloid boldine, defined as the main component of boldo tea [4]. The concentration of alkaloids in boldo leaves is estimated at $0.4 \%$, and the concentration of boldine can reach more than $12 \%$ [5].

Indeed, a wide range of biological effects has been attributed to boldine. Boldine has been shown to possess antioxidant activity and anti-inflammatory effects, which is why it is often studied for oxidative stress-associated diseases. For instance, the protective effect of boldine on oxidative mitochondrial damage in streptozotocin-induced diabetic rats has been described [6], and the reduction on oxidative stress to induce its gastroprotective properties [7]. As for the pharmacological action on the cardiovascular and renal systems to control hypertension and pathologies such as diabetes, studies have shown the action of boldine in improving the endothelial function in diabetic mice through the inhibition of vascular oxidative stress and endothelial dysfunction [8]. In addition, studies have demonstrated that boldine treatment exerts endothelial protective effects in spontaneously hypertensive rats through the inhibition of NADPH-mediated superoxide production [9]. Boldine improved kidney damage in renovascular hypertension induced by the Goldblatt two-kidney one-clip model [10] and showed a renoprotective action in streptozotocin-induced diabetes in rats [11].

Despite the widespread use of the alkaloid boldine, its mechanism of action on renal function remains unclear. Considering the need for new approaches to the treatment of hypertension or contributing to the renoprotective actions against hypertension, this study aimed to investigate boldine's vasodilatory action by using an isolated and perfused rat kidney model to verify the hypothesis that boldine causes the direct relaxation of renal arteries. The mechanisms responsible for renal vasodilator actions were also explored.

\section{Materials and Methods}

2.1. Drugs. Boldine ( $\geq 98 \%$ purity) was purchased from Sigma-Aldrich (St. Louis, MO, USA). Heparin was obtained from Cristália, (São Paulo, SP, Brazil). Xylazine and ketamine hydrochloride were obtained from Vetec (Vetec, Duque de Caxias, RJ, Brazil). Acetylcholine chloride, apamin, charybdotoxin, dextrose, glibenclamide, iberiotoxin, indomethacin, tetraethylammonium chloride (TEA), $\mathrm{N} \omega$ nitro-L-arginine methyl ester (L-NAME), phenylephrine, sodium deoxycholate, $\mathrm{NaCl}, \mathrm{NaHCO}_{3}, \mathrm{KCl}, \mathrm{CaCl}_{2}, \mathrm{MgSO}_{4}$, $\mathrm{KH}_{2} \mathrm{PO}_{4}$, and ethylenediaminetetraacetic acid (EDTA) were purchased from Sigma-Aldrich (St. Louis, MO, USA).

2.2. Animals. Male Wistar rats, 3 months old, were obtained from the animal facility of the University of Vale do Itajaí
(UNIVALI). The animals were kept at controlled room temperature $\left(22 \pm 2^{\circ} \mathrm{C}\right)$, 12-hour light/dark cycle, with free access to water and chow. All methodologies and procedures used here were submitted and approved by the Ethics Committee on Animal Use of UNIVALI, under authorization number $022 / 19 \mathrm{p}$ and followed all the National Control Council of Animal Experimentation recommendations.

2.3. Isolation and Perfusion of the Rat Kidney. To avoid the appearance of clots in the renal vascular bed during the kidney isolation and perfusion procedure, the animals were previously treated with heparin (30 UI, by intraperitoneal route), 5 to $10 \mathrm{~min}$ before the administration of the anesthetic agent. The rats were then anesthetized with $80 \mathrm{mg} / \mathrm{kg}$ ketamine plus $10 \mathrm{mg} / \mathrm{kg}$ xylazine by intraperitoneal route. After obtaining deep anesthesia, a laparotomy was performed, allowing access to all the animal's viscera. The intestine was shifted to the right side, allowing visualization of the left kidney and dissection of the abdominal aorta. During these procedures, the viscera, especially the left kidney, were kept moist with surgical gauze soaked in physiological saline solution. With the aid of a surgical thread, the left ureter was ligated, preventing urinary flow and, consequently, the production of urine by the kidney. Another surgical wire was placed in the abdominal aorta artery, between the right and left renal arteries, to direct blood flow only to the left side. Blood flow in the aorta artery was interrupted below the right renal artery. Then, a small incision was made in the aorta artery, allowing the insertion of a catheter-directed to the left renal artery and fixed to the aorta artery with surgical threads. The surgical thread positioned over the abdominal aorta was tied, interrupting the renal flow, and a peristaltic perfusion pump was activated, starting the perfusion process. In the continuous perfusion process, the kidney was removed from the abdominal cavity and placed in a plate to remove the adjacent fat and adrenal gland, to avoid the influence of the adrenal on the renal vascular bed during the experimentation period. Then, the kidney was placed in a chamber containing $100 \mathrm{ml}$ of physiological saline solution (PSS; $119 \mathrm{mM} \mathrm{NaCl}, 4.7 \mathrm{mM} \mathrm{KCl}, 2.4 \mathrm{mM} \mathrm{CaCl}_{2}, 1.2 \mathrm{mM}$

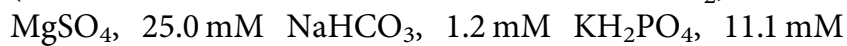
dextrose, and $0.03 \mathrm{mM}$ EDTA) and coupled to the perfusion system, kept at a temperature of $37^{\circ} \mathrm{C}$, constantly aerated with $95 \% \mathrm{O}_{2}$ and $5 \% \mathrm{CO}_{2}$, with a constant flow of $4 \mathrm{ml} / \mathrm{min}$. A period of $30 \mathrm{~min}$ was respected before starting the experimental evaluation. The recording of perfusion pressure was performed through a pressure transducer coupled to the perfusion system, connected to a computerized polygraph with specific integration software (PowerLab system and Chart 7.1 software, ADInstruments, Castle Hill, Australia). A diagram of the isolated perfused kidney experimental setup is displayed in Figure 1.

2.4. Evaluation of the Effects and Mechanisms of Boldine on the Renal Arteries. After a stabilization time of $30 \mathrm{~min}$, tissue integrity was verified with a bolus injection of $120 \mathrm{mmol}$ $\mathrm{KCl}$. The integrity of the endothelium was checked $20 \mathrm{~min}$ 


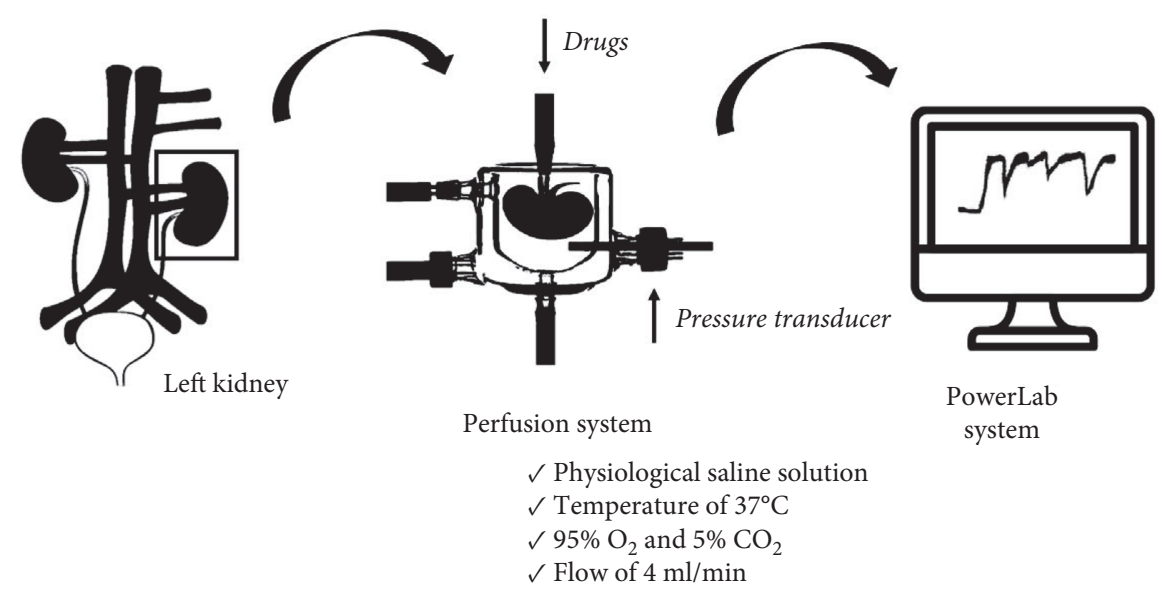

FIGURE 1: Diagram of the isolated perfused kidney experimental setup.

later with the addition of phenylephrine $(300 \mathrm{nmol})$ followed by acetylcholine $(300 \mathrm{nmol})$. A further $20 \mathrm{~min}$ period waited, and then the preparations were continuously perfused with PSS containing phenylephrine $(3 \mu \mathrm{M})$, which is enough to induce a sustained increase in renal perfusion pressure. After stabilization in the increase in perfusion pressure, the preparations received bolus injections containing 10, 30, 100 , and $300 \mathrm{nmol}$ of boldine, and the reduction in perfusion pressure was evaluated. The bolus injections of the tested substances were made in a final volume of 10 or $30 \mu \mathrm{l}$ through access close to the preparation, with a minimal time interval of $3 \mathrm{~min}$ between doses. Some kidney preparations were perfused with PSS that contained sodium deoxycholate $(1.8 \mathrm{mg} / \mathrm{ml})$ for $30 \mathrm{~s}$ to chemically remove the renal arteries' endothelium. After the infusion of sodium deoxycholate, regular PSS was perfused for $40 \mathrm{~min}$ for stabilization. The lack of vasodilatation confirmed the endothelium removal after a bolus injection of acetylcholine. A dose-response curve $(30,100$, and $300 \mathrm{nmol})$ of boldine was generated for preparations without an endothelium. Responses were recorded $10 \mathrm{~s}$ after administration. Changes in perfusion pressure (in $\mathrm{mmHg}$ ) were recorded and compared between groups.

In another experimental set, using preparations with an intact endothelium, the preparations were perfused with PSS that contained $3 \mu \mathrm{M}$ phenylephrine plus the following agents: $100 \mu \mathrm{ML}-\mathrm{NAME}$ (nonselective nitric oxide synthase inhibitor), $1 \mu \mathrm{M}$ indomethacin (nonselective cyclooxygenase inhibitor), $40 \mathrm{mM} \mathrm{KCl}\left(\mathrm{K}^{+}\right.$-mediated depolarization), $10 \mathrm{mM}$ TEA (nonspecific potassium channel blocker), $10 \mu \mathrm{M}$ glibenclamide (selective ATP-sensitive $\mathrm{K}^{+}$channels blocker), apamin $10 \mathrm{nM}$ (selective small-conductance $\mathrm{Ca}^{2+}$ activated $\mathrm{K}^{+}$channel blocker), iberiotoxin (selective highconductance $\mathrm{Ca}^{2+}$-activated $\mathrm{K}^{+}$channel blocker), $1 \mathrm{nM}$ charybdotoxin (selective high- and intermediate-conductance $\mathrm{Ca}^{2+}$-activated $\mathrm{K}^{+}$channel blocker). After $15 \mathrm{~min}$ of perfusion, boldine $(30,100$, and $300 \mathrm{nmol})$ was injected. Its ability to reduce perfusion pressure was compared with the results obtained with the control preparations perfused only with the vehicle.
2.5. Statistical Analysis. The results are expressed as the mean \pm standard error of the mean from six preparations in each group. The statistical analyses were performed using a one-way analysis of variance (ANOVA) followed by Bonferroni's post hoc test. Values of $p<0.05$ were considered statistically significant. The statistical analyses were performed using the GraphPad Prism software version 6.00 for Windows (GraphPad, La Jolla, CA, USA).

\section{Results and Discussion}

The vasodilator effect on renal arteries using isolated and perfused rat kidneys has been a heavily used strategy to assess the hemodynamic actions of isolated compounds, with a closer approximation to the mechanism of action, given the ability to assess different molecular targets [12]. In the present study, the administration of boldine $(30,100$, and $300 \mathrm{nmol}$ ) in the vascular bed of the kidney induced a dose-dependent dilatory result (Figure 2(c)), thus answering the initial hypothesis of the work that discussed the possibility of boldine having a vasodilating action in the renal arterial bed. This is the first study to demonstrate the relaxing effects of boldine on the renal vascular bed. However, the relaxing effect of boldine on other vascular tissues was first described in 1996, where Chen et al. demonstrated the vasodilating action of this alkaloid in isolated rat thoracic aorta [13].

Based on this positive result, investigations were carried out on the involvement of the endothelium and the underlying mechanisms related to relaxing actions. As depicted in Figure 2(d), the effects of boldine in the preparations previously administered with sodium deoxycholate (i.e., to remove the endothelium) were completely absent (Figure 2(d)), indicating that the functional endothelium is essential for its vasodilatory action. Correspondingly, the effects of all doses of boldine were prevented in preparations that were treated with the nonselective nitric oxide synthase inhibitor L-NAME (Figure 3(a)), while in the preparations perfused with the nonselective cyclooxygenase enzyme inhibitor indomethacin, the vasorelaxant effects of boldine 
<smiles>COc1cc2c(cc1O)C[C@H]1c3c(cc(O)c(OC)c3-2)CCN1C</smiles>

(a)

Boldine (nmol)

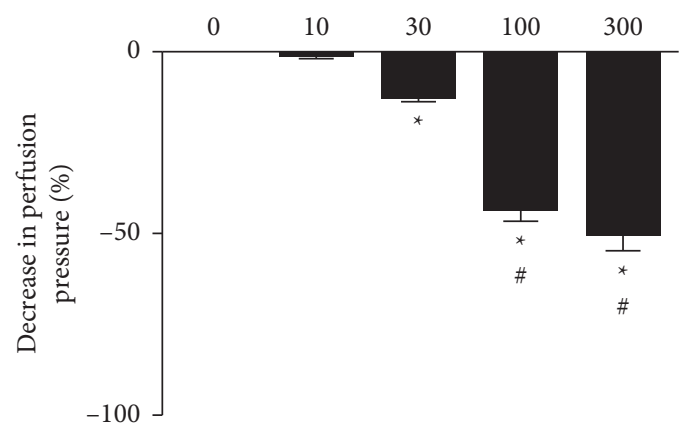

(c)

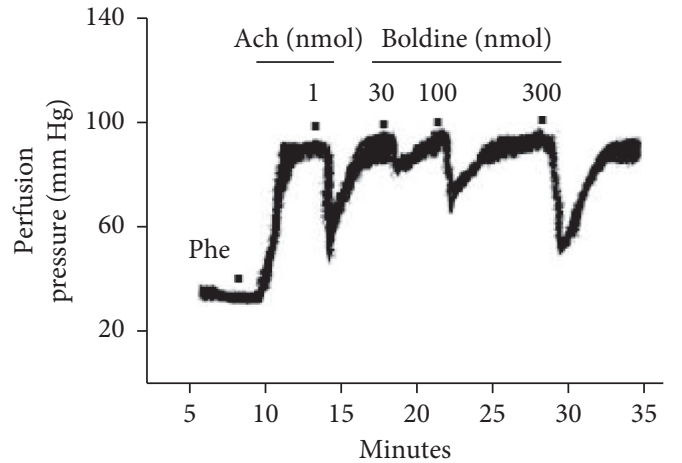

(b)

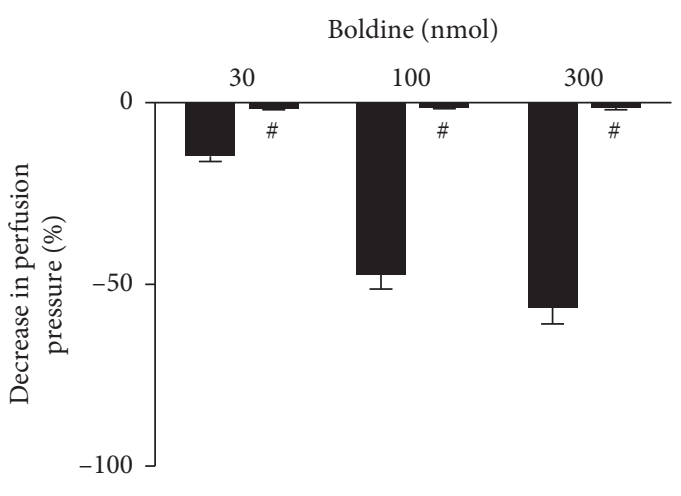

End +

End -

(d)

Figure 2: Boldine dose-dependently induced vasorelaxation in isolated and perfused kidneys. (a) Molecular structure of boldine. (b) Trace recording of kidney perfusion pressure showing the effects of acetylcholine (ACh) and boldine. (c) Effects of boldine on perfusion pressure in endothelium-intact isolated kidneys. (d) Effects of boldine on endothelium-intact (End+) and endothelium-denuded (End-) preparations. The data are expressed as the mean \pm SEM from six experiments. ${ }^{*} p<0.05$, compared with perfusion pressure after PSS administration (identified as the number 0 ); ${ }^{\#} p<0.05$, compared with the previous dose of boldine (a) or endothelium-denuded preparations (b).

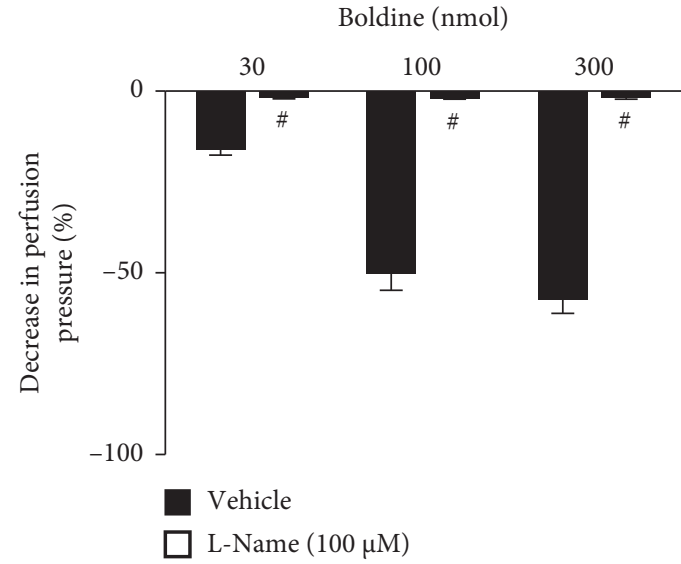

(a)

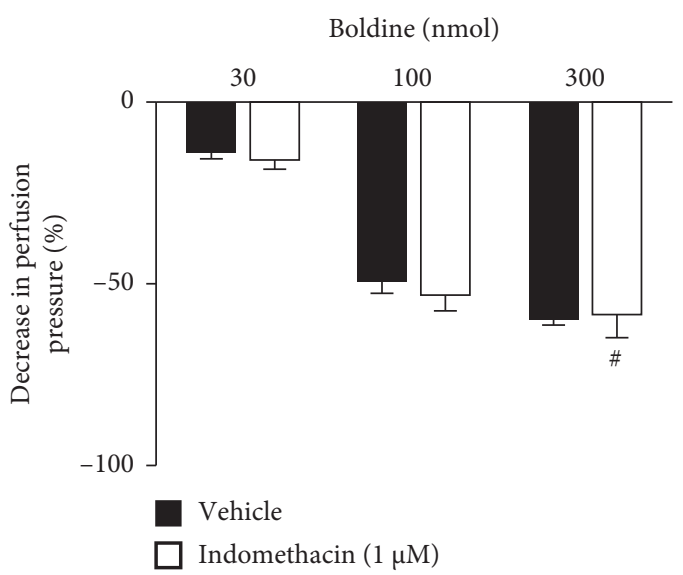

(b)

FIGURE 3: Role of nitric oxide and prostanoids in the vasodilatory effects of boldine. Effects of boldine on endothelium-intact kidney preparations that were perfused with (a) L-NAME or (b) indomethacin. The data are expressed as the mean \pm SEM from six experiments. ${ }^{\#} p<0.05$, compared with the vehicle-only perfused preparations. 


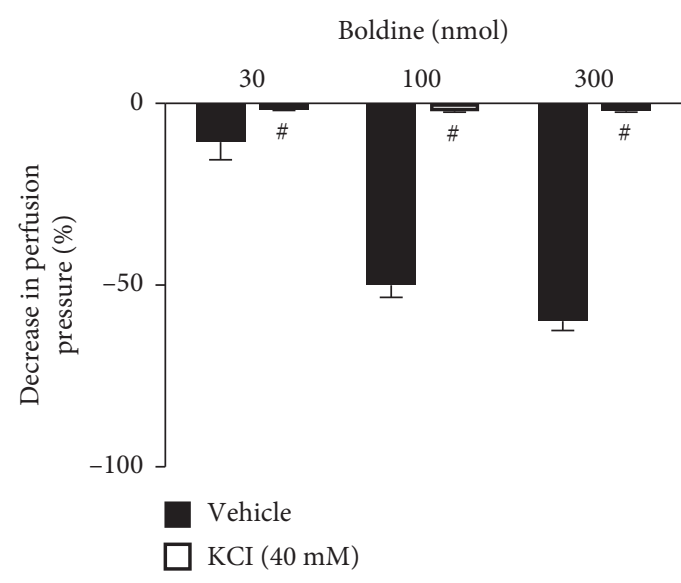

(a)

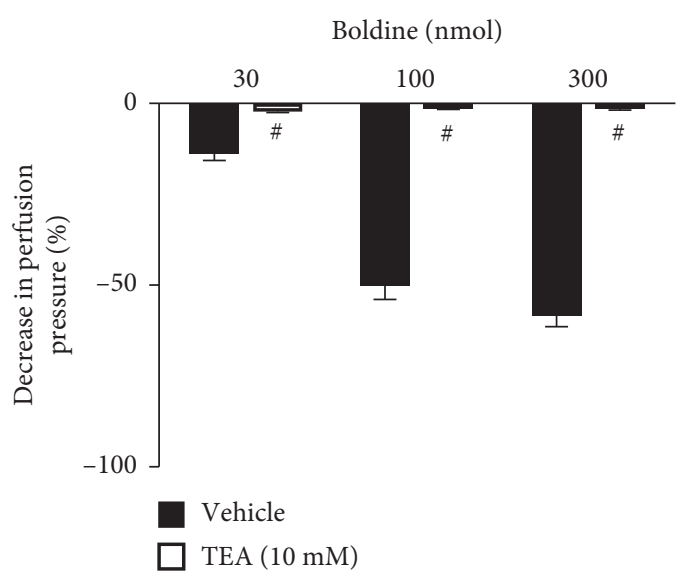

(b)

Figure 4: Effect of potassium channels on the vasodilatory effect of boldine. Effects of boldine on endothelium-intact kidney preparations that were perfused with (a) $\mathrm{KCl}$ or (b) TEA. The data are expressed as the mean \pm SEM from six experiments. ${ }^{\#} p<0.05$, compared with the vehicle-only perfused preparations.

remained unchanged (Figure 3(b)), indicating that endothelium-dependent relaxant properties of boldine were dependent of nitric oxide (NO) generation and independent of prostanoids production.

The main endothelium-derived relaxant factor is NO, which is considered one of the main mediators of cellular processes. In blood vessels, NO is produced in endothelial cells from L-arginine, having a vasodilating action. It diffuses to the smooth muscle cells interacting with the soluble guanylate cyclase enzyme making it active, causing the formation of cyclic guanosine monophosphate, which results in the relaxation of the vascular smooth muscle cell $[14,15]$. Considering that endothelial removal or the suppression of NO production through the administration of L-NAME completely prevented the vascular effects of boldine, our findings suggest that the endothelium performed a crucial function in decreasing perfusion pressure induced by boldine. Indeed, the actions of boldine on vascular endothelium have already been described in the literature. Boldine treatment enhanced the maximal relaxation to acetylcholine in spontaneously hypertensive rats aorta [9], improved the endothelium-dependent relaxation in the aortas of streptozotocintreated diabetic rats [16], and improved endothelium-dependent relaxation in aortas of diabetic mice [17].

To verify the actions related to $\mathrm{K}^{+}$channels, the preparations were perfused with a nutrient solution in which $40 \mathrm{mM} \mathrm{KCl}$ was added, which induces $\mathrm{K}^{+}$-mediated depolarization, and TEA, a nonselective $\mathrm{K}^{+}$-channel blocker (Figures 4(a) and 4(b), respectively). It was observed that both treatments blocked the vasorelaxant effects induced by boldine, suggesting a predominant role of $\mathrm{K}^{+}$channels in the vasodilatory effects of this compound. $\mathrm{K}^{+}$channels are protein structures present in different types of cells, function as pores in membranes that allow the passage of $\mathrm{K}^{+}$. They are divided into 4 major classes: voltage-dependent $\mathrm{K}^{+}$channels, ATP-sensitive $\mathrm{K}^{+}$channels, inward-rectifier $\mathrm{K}^{+}$channels, and $\mathrm{Ca}^{2+}$-activated $\mathrm{K}^{+}$channels [18-20]. The treatment with glibenclamide, an ATP-sensitive $\mathrm{K}^{+}$channel blocker, maintained the vasorelaxant action of boldine unchanged in all doses used (Figure 5(a)). Similarly, the perfusion with charybdotoxin, a selective high- and intermediate-conductance $\mathrm{Ca}^{2+}$-activated $\mathrm{K}^{+}$channel blocker (Figure 6(a)), and iberiotoxin, a selective high-conductance $\mathrm{Ca}^{2+}$-activated $\mathrm{K}^{+}$ channel blocker (Figure 6(b)), did not modify the vasodilatory action of boldine. On the other hand, the perfusion with apamin, a selective small-conductance $\mathrm{Ca}^{2+}$-activated $\mathrm{K}^{+}$channel blocker, completely prevented the vasodilatory action of boldine at all doses tested (Figure 5(b)), indicating that this $\mathrm{K}^{+}$channel subtype appears to be crucial for the relaxing actions evoked by boldine. In summary, considering that the downstream targets of the nitric oxide pathway in vessels include the opening of $\mathrm{K}^{+}$channels $[21,22]$, this set of results suggests that boldine-mediated endothelium-dependent vasodilation in renal arteries depends on the opening of small-conductance $\mathrm{Ca}^{2+}$-activated $\mathrm{K}^{+}$channels induced by nitric oxide in smooth muscle cells.

It is noteworthy that, in recent years, many compounds isolated from medicinal plants have been studied about their renal actions, revealing important vasodilating, diuretic, antiurolithic, and protective actions against hypertensive damage. Nothofagin, a mono-C-glycoside of $4,2^{\prime}, 4^{\prime}, 6^{\prime}$-tetrahydroxy-dihydrochalcone found in Leandra dasytricha leaves, demonstrated the ability to induce diuresis [23], renoprotection [24], vasodilation [12], and hypotensive effect [25]. Different compounds from the xanthone classes isolated from Garcinia achachairu branches revealed acute diuretic actions $[26,27]$, prolonged diuretic and renoprotective effects [28], and antiurolithic properties [29]. Besides, glycosylated flavonoids obtained from the leaves of Bauhinia forficata revealed vasodilator [30], diuretic, and kidney protective effects [31].

However, although the results described herein undoubtedly point toward the participation of $\mathrm{Ca}^{2+}$-activated $\mathrm{K}^{+}$channels in the renal effects induced by boldine, further studies are needed to investigate other molecular targets and subtypes of channels by using different inhibitors combined approaches. Besides, another important limitation of the 


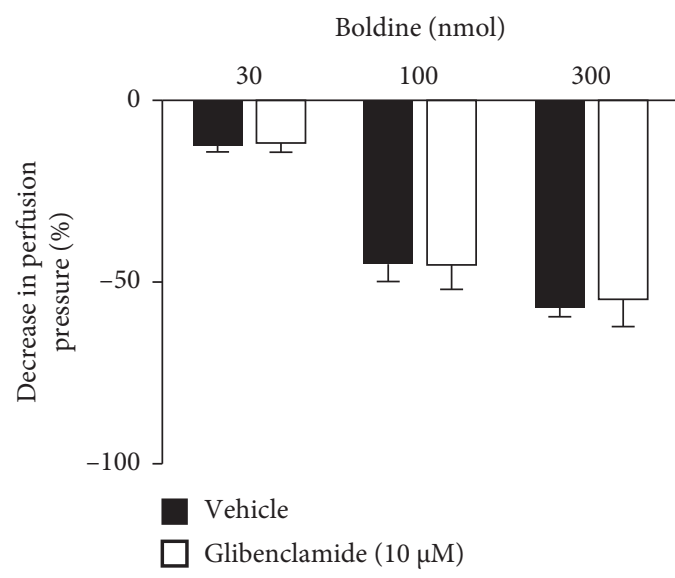

(a)

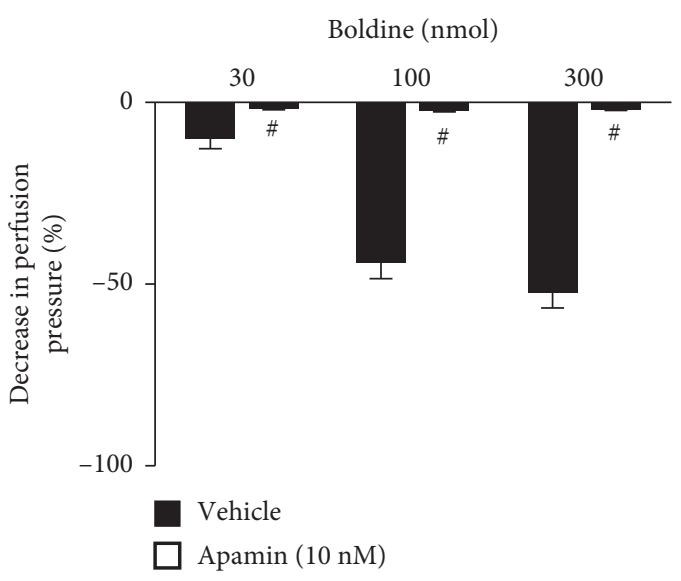

(b)

FIGURE 5: Effect of potassium channel subtype blockers on the vasodilatory effect of boldine. Effects of boldine on endothelium-intact kidney preparations that were perfused with (a) glibenclamide or (b) apamin. The data are expressed as the mean \pm SEM from six experiments. ${ }^{\#} p<0.05$, compared with the vehicle-only perfused preparations.

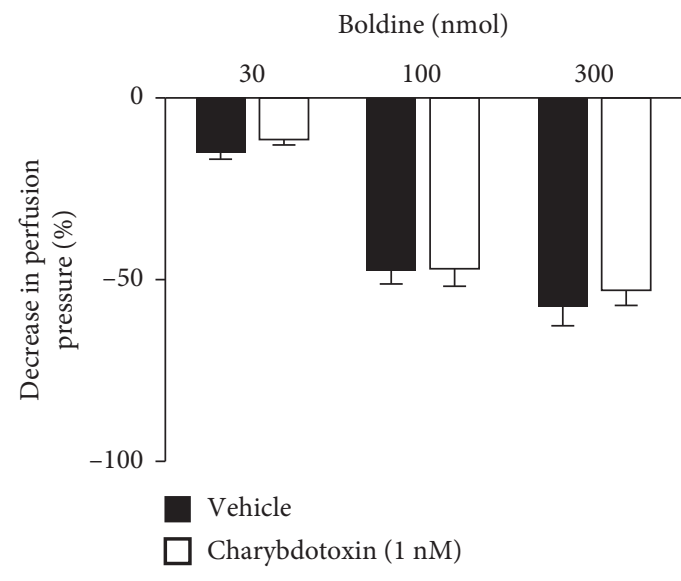

(a)

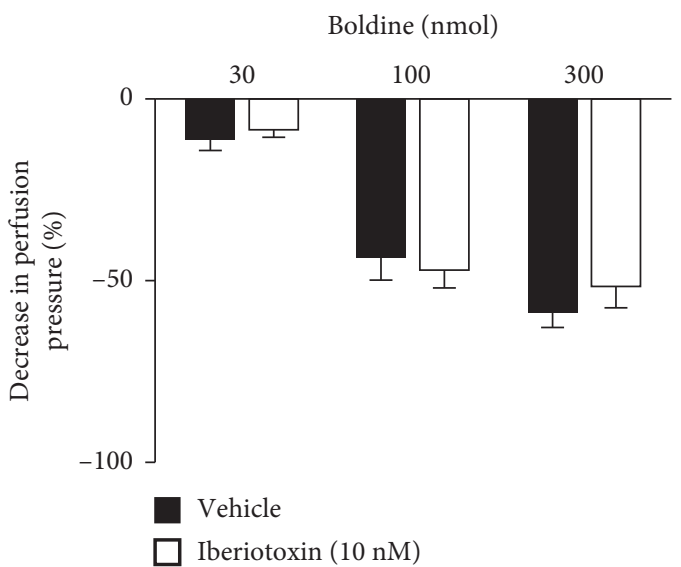

(b)

FIGURE 6: Effect of potassium channel subtype blockers on the vasodilatory effect of boldine. Effects of boldine on endothelium-intact kidney preparations that were perfused with (a) charybdotoxin or (b) iberiotoxin. The data are expressed as the mean \pm SEM from six experiments.

study is that we were unable to explore the receptor involved in the vasodilatory effect of boldine, which remains to be studied in the future. Considering the actions already described in the literature for this alkaloid, this study adds about the renal vasodilator effect, contributing to a better understanding of boldine's potential to be used as pharmacotherapy or dietary supplement.

\section{Data Availability}

The data used to support the findings of this study are available on request to the corresponding author.

\section{Conflicts of Interest}

The authors declare that they have no conflicts of interest to disclose.

\section{Authors' Contributions}

PDS and AGJ designed the study, acquired funding, and prepared the article. KGTM, VMBS, LMS, and RCVS performed the experiments and generated and analyzed the data. All authors read and approved the final version of the article.

\section{Acknowledgments}

This work was supported by grants from the National Council for Scientific and Technological Development (CNPq; no. 449464/2014-8 and 407685/2018-9), Higher Education Personnel Improvement Coordination (CAPES), Scientific Research Support Foundation and Technological Sciences of the State of Santa Catarina (FAPESC), and University of Vale do Itajaí (UNIVALI). 


\section{References}

[1] M. d. F. Agra, P. F. d. Freitas, and J. M. Barbosa-Filho, "Synopsis of the plants known as medicinal and poisonous in Northeast of Brazil," Revista Brasileira de Farmacognosia, vol. 17, no. 1, pp. 114-140, 2007.

[2] M. G. L. Brandão, G. P. Cosenza, R. A. Moreira, and R. L. M. Monte-Mor, "Medicinal plants and other botanical products from the Brazilian Official Pharmacopoeia," Rev Bras Farmacogn, vol. 16, pp. 408-420, 2006.

[3] C. Viegas, V. S. Bolzani, J. Eliezer, and E. J. Barreiro, "The natural products and the modern medicinal chemistry," Quimica Nova, vol. 29, no. 2, 2006.

[4] A. L. T. G. Ruiz, D. Tafarello, V. H. S. Souza, and J. E. Carvalho, "Pharmacology and toxicology of Peumus boldus and Baccharis genistelloides," Rev. bras. Farmacognosia.vol. 18, no. 2, 2008.

[5] P. O’Brien, C. Carrasco-Pozo, and H. Speisky, "Boldine and its antioxidant or health-promoting properties," Chemico-Biological Interactions, vol. 159, pp. 1-17, 2006.

[6] Y. Y. Jang, J. H. Song, Y. K. Shin, E. S. Han, and C. S. Lee, "Protective effect of boldine on oxidative mitochondrial damage in streptozotocin-induced diabetic rats," Pharmacological Research, vol. 42, no. 4, pp. 361-371, 2000.

[7] T. Boeing, L. N. B. Mariano, A. C. Dos Santos et al., "Gastroprotective effect of the alkaloid boldine: involvement of non-protein sulfhydryl groups, prostanoids and reduction on oxidative stress," Chemico-Biological Interactions, vol. 327, Article ID 109166, 2020.

[8] Y. S. Lau, W. C. Ling, D. Murugan, and M. R. Mustafa, "Boldine ameliorates vascular oxidative stress and endothelial dysfunction," Journal of Cardiovascular Pharmacology, vol. 65, no. 6, pp. 522-531, 2015.

[9] Y.-S. Lau, A. Machha, F. I. Achike, D. Murugan, and M. R. Mustafa, "The aporphine alkaloid boldine improves endothelial function in spontaneously hypertensive rats," Experimental Biology and Medicine, vol. 237, no. 1, pp. 93-98, 2012.

[10] G. I. Gómez and V. Velarde, "Boldine improves kidney damage in the Goldblatt 2K1C model avoiding the increase in TGF- $\beta$," International Journal of Molecular Sciences, vol. 19, no. 7, p. 1864, 2018.

[11] R. Hernández-Salinas, A. Z. Vielma, M. N. Arismendi, M. P. Boric, J. C. Sáez, and V. Velarde, "Boldine prevents renal alterations in diabetic rats," Journal of Diabetes Research, vol. 2013, Article ID 593672, , 2013.

[12] A. A. M. Marques, C. H. F. da Silva, P. de Souza et al., "Nitric oxide and $\mathrm{Ca} 2+$-activated high-conductance $\mathrm{K}+$ channels mediate nothofagin-induced endothelium-dependent vasodilation in the perfused rat kidney," Chemico-Biological Interactions, vol. 327, Article ID 109182, 2020.

[13] K. S. Chen, F. N. Ko, C. M. Teng, and Y. C. Wu, "Antiplatelet and vasorelaxing actions of some aporphinoids," Planta Medica, vol. 62, no. 2, pp. 133-136, 1996.

[14] G. A. Shiekh, T. Ayub, S. N. Khan, R. Dar, and K. I. Andrabi, "Reduced nitrate level in individuals with hypertension and diabetes," Journal of Cardiovascular Disease Research, vol. 2, no. 3, pp. 172-176, 2011.

[15] E. S. Underbakke, A. T. Iavarone, M. J. Chalmers et al., "Nitric oxide-induced conformational changes in soluble guanylate cyclase," Structure, vol. 22, no. 4, pp. 602-611, 2014.

[16] Y. S. Lau, X. Y. Tian, Y. Huang, D. Murugan, F. I. Achike, and M. R. Mustafa, "Boldine protects endothelial function in hyperglycemia-induced oxidative stress through an antioxidant mechanism," Biochemical Pharmacology, vol. 85, no. 3, pp. 367-375, 2013a.

[17] Y. S. Lau, X. Y. Tian, M. R. Mustafa et al., "Boldine improves endothelial function in diabeticdb/dbmice through inhibition of angiotensin II-mediated BMP4-oxidative stress cascade," British Journal of Pharmacology, vol. 170, no. 6, pp. 11901198, 2013b.

[18] M. Baranowska, H. Kozłowska, A. Korbut, and B. Malinowska, "Potassium channels in blood vessels: their role in health and disease," Postepy Higieny I Medycyny Doswladczalnej, vol. 61, pp. 596-605, 2007.

[19] W. F. Jackson, "Potassium channels in the peripheral microcirculation," Microcirculation, vol. 12, no. 1, pp. 113-127, 2005.

[20] B. F. Palmer and D. J. Clegg, "Physiology and pathophysiology of potassium homeostasis," Advances in Physiology Education, vol. 40, no. 4, pp. 480-490, 2016.

[21] S. L. Archer, J. M. Huang, V. Hampl, D. P. Nelson, P. J. Shultz, and E. K. Weir, "Nitric oxide and cGMP cause vasorelaxation by activation of a charybdotoxin-sensitive $\mathrm{K}$ channel by cGMP-dependent protein kinase," Proceedings of the National Academy of Sciences, vol. 91, no. 16, pp. 7583-7587, 1994.

[22] V. M. Bolotina, S. Najibi, J. J. Palacino, P. J. Pagano, and R. A. Cohen, "Nitric oxide directly activates calcium-dependent potassium channels in vascular smooth muscle," Nature, vol. 368, no. 6474, pp. 850-853, 1994.

[23] C. L. B. de Almeida, T. Boeing, L. B. Somensi et al., "Diuretic, natriuretic and potassium-sparing effect of nothofagin isolated from Leandra dasytricha (A. Gray) Cogn. leaves in normotensive and hypertensive rats," Chemico-Biological Interactions, vol. 268, pp. 103-110, 2017.

[24] C. L. B. de Almeida, V. Cechinel-Filho, T. Boeing et al., "Prolonged diuretic and saluretic effect of nothofagin isolated from Leandra dasytricha (A. Gray) Cogn. leaves in normotensive and hypertensive rats: role of antioxidant system and renal protection," Chemico-Biological Interactions, vol. 279, pp. 227-233, 2018.

[25] C. H. da Silva, R. A. Palozi, P. de Souza et al., "Nitric oxide/ cGMP signaling pathway and potassium channels contribute to hypotensive effects of nothofagin," Minerva Cardioangiologica, vol. 68, no. 6, pp. 602-608, 2020.

[26] L. N. Bolda Mariano, T. Boeing, R. d. C. M. V. d. A. F. da Silva et al., "1,3,5,6-Tetrahydroxyxanthone, a natural xanthone, induces diuresis and saluresis in normotensive and hypertensive rats," Chemico-Biological Interactions, vol. 311, Article ID 108778, 2019.

[27] L. N. Bolda Mariano, T. Boeing, V. Cechinel-Filho, R. Niero, L. Mota da Silva, and P. de Souza, "The acute diuretic effects with low-doses of natural prenylated xanthones in rats," European Journal of Pharmacology, vol. 884, Article ID 173432, 2020.

[28] L. N. Bolda Mariano, T. Boeing, V. Cechinel Filho et al., "Prolonged diuretic and renoprotective effects of a xanthone obtained from Garcinia achachairu rusby in normotensive and hypertensive rats," Evid-based Complement Alternative Medicine, vol. 2021, Article ID 5510053, 9 pages, 2021.

[29] L. N. B. Mariano, T. Boeing, V. Cechinel Filho, R. Niero, L. Mota da Silva, and P. de Souza, "1,3,5,6-tetrahydroxyxanthone promotes diuresis, renal protection and antiurolithic properties in normotensive and hypertensive rats," Journal of Pharmacy and Pharmacology, vol. 73, no. 5, pp. 700-708, 2021.

[30] C. C. Cechinel-Zanchett, R. d. C. M. V. d. A. F. da Silva, A. Tenfen et al., "Bauhinia forficata link, a Brazilian medicinal 
plant traditionally used to treat cardiovascular disorders, exerts endothelium-dependent and independent vasorelaxation in thoracic aorta of normotensive and hypertensive rats," Journal of Ethnopharmacology, vol. 243, p. 112118, 2019.

[31] C. C. Cechinel-Zanchett, L. N. Bolda Mariano, T. Boeing et al., "Diuretic and renal protective effect of kaempferol 3O-Alpha-l-rhamnoside (afzelin) in normotensive and hypertensive rats," Journal of Natural Products, vol. 83, no. 6, pp. 1980-1989, 2020. 